\title{
Association of Matrix Metalloproteinase1-1607 1G>2G Polymorphism and Lung Cancer Risk: An Update by Meta-Analysis
}

\author{
Yue Ma ${ }^{1}$, Xi Yang ${ }^{2}$, Yu-Ping Xie ${ }^{3}$, Cheng $\mathrm{Yi}^{2}$, Fen $\mathrm{Zhao}^{3}$, Ying Huang ${ }^{1 *}$
}

\begin{abstract}
Objective: The association between matrix metalloproteinase1 (MMP1)-1607 1G $>2 \mathrm{G}$ polymorphism and lung cancer risk is still inconclusive and inconsistent. We conducted a meta-analysis to estimate the potential relationship between MMP1-1607 1G>2G polymorphism and lung cancer risk. Methods: The comprehensive searches of the PubMed, Web of Science, Medline, CBM, CNKI, Weipu, and Wanfang databases, published up to Nov 10, 2018. Statistical analyses were performed with Review Manager 5.3 software. Results: A total of 14 relevant studies containing 6068 cases and 5860 controls were included in the study. The results indicated that MMP1-1607 1G>2G polymorphism was significantly associated with increased lung cancer risk under four models: $2 \mathrm{G}$ vs. $1 \mathrm{G}$ model (pooled $\mathrm{OR}=1.19,95 \% \mathrm{CI}=1.05-1.34$, $\mathrm{P}<0.0001$ ); $2 \mathrm{G} / 2 \mathrm{G}$ vs. $1 \mathrm{G} / 1 \mathrm{G}$ (pooled $\mathrm{OR}=1.34,95 \% \mathrm{CI}=1.09-1.64, \mathrm{P}=0.003$ ); $2 \mathrm{G} / 2 \mathrm{G}$ vs. $1 \mathrm{G} / 1 \mathrm{G}+1 \mathrm{G} / 2 \mathrm{G}$ (pooled $\mathrm{OR}=1.26,95 \% \mathrm{CI}=1.06-1.49, \mathrm{P}<0.0001$ ); $2 \mathrm{G} / 2 \mathrm{G}+1 \mathrm{G} / 2 \mathrm{G}$ vs. $1 \mathrm{G} / 1 \mathrm{G}$ (pooled $\mathrm{OR}=1.21,95 \% \mathrm{CI}=1.05-1.40, \mathrm{P}$ $=0.01)$. Subgroup analyses showed that there was a higher increase in smoking status under three models: $2 \mathrm{G} / 2 \mathrm{G}$ vs. $1 \mathrm{G} / 1 \mathrm{G}$ (pooled $\mathrm{OR}=2.07,95 \% \mathrm{CI}=1.14-3.77, \mathrm{P}=0.02$ ); $2 \mathrm{G} / 2 \mathrm{G}$ vs. $1 \mathrm{G} / 1 \mathrm{G}+1 \mathrm{G} / 2 \mathrm{G}$ (pooled $\mathrm{OR}=1.71,95 \% \mathrm{CI}$ $=1.17-2.52, \mathrm{P}=0.006$ ) $; 2 \mathrm{G} / 2 \mathrm{G}+1 \mathrm{G} / 2 \mathrm{G}$ vs. $1 \mathrm{G} / 1 \mathrm{G}$ (pooled $\mathrm{OR}=2.03,95 \% \mathrm{CI}=1.14-3.62, \mathrm{P}=0.02$ ). In addition, subgroup analyses by ethnicity further identified the significant association in Asians. Non-smoking population and ethnicity among Caucasian had no relationship with lung cancer susceptibility in four models. Conclusion: Our study suggested that MMP1-1607 1G>2G polymorphism was a risk factor for developing lung cancer risk.
\end{abstract}

Keywords: matrix metalloproteinase1 (MMP1)- lung cancer- polymorphism- meta-analysis

Asian Pac J Cancer Prev, 20 (6), 1841-1847

\section{Introduction}

Lung cancer (LC), as the most common cancer worldwide, accounted for 2.1 million new LC cases and 1.8 million deaths predicted in 2018 (McIntyre and Ganti, 2017; Bray et al., 2018). Now, the mechanism of LC still remains unclear. The major risk factors are involved in environmental pollution, genetic susceptibility, tobacco smoking and diet (Malhotra et al., 2016). Although these factors have been demonstrated to promote the incidence of LC, not all individuals exposed in the same environment develop the disease. This also indicates that other causes, such as genetic variants, may lead to the development of LC. In recent years, numerous published studies have focused on the association of genetic variants with LC susceptibility, and among which, the matrix metalloproteinase (MMP) gene has been extensively studied.

MMP is a family of zinc-dependent proteolytic enzymes that are able to degrade the components of the extracellular matrix (ECM) including basement membranes and collagen (Nelson et al., 2000). MMP1, one member of the MMP, performs a critical function in degrading the interstitial collagen types I, II, III and mediating pathways of angiogenesis (Vincenti et al., 1996). The expression level of MMP1 can be affected by a functional single nucleotide polymorphism (MMP1-1607 1G>2G). 1607 1G $>2 \mathrm{G}$ in the MMP1 gene contains a single-guanine insertion/deletion $2 \mathrm{G}$ to $1 \mathrm{G}$ polymorphism located at the MMP1 promoter region (Hu et al., 2012). The $2 \mathrm{G}$ allele has been associated with higher transcriptional activity due to creating a transcription factor binding site (Rutter et al., 1998). Despite the fact that increasing studies on the association of genetic risk of $16071 \mathrm{G}>2 \mathrm{G}$ polymorphism in the MMP1 gene for LC have been published in the past decades, the results remain inconsistent and controversial. To providing a more comprehensive conclusion, we performed a meta-analysis

${ }^{1}$ Department of Pathophysiology, West China School of Basic Medical Sciences and Forensic Medicine, ${ }^{2}$ Department of Medical Oncology, Cancer Center, West China Hospital, Sichuan University, ${ }^{3}$ Department of Oncology, Chengdu First People's Hospital, Chengdu 610041, Sichuan Province, China.*For Correspondence: huangying68@163.com. Yue Ma and, Xi Yang and, Yu-ping Xie have equal contribution in this study. 
based on 14 eligible case-control studies to evaluate the associations between MMP1-1607 1G $>2 \mathrm{G}$ polymorphism and LC risk.

\section{Methods and Materials}

\section{Literature search and study selection criteria}

The PubMed, Web of Science, Medline, Chinese biomedical (CBM), China national knowledge infrastructure (CNKI), Weipu, and Wanfang databases were searched to identify all articles by using the following keywords (last search was updated on Nov 10, 2018): "MMP1 or matrix metalloproteinase1" and "lung tumor or lung cancer or lung neoplasm or lung carcinoma" and "polymorphism or variant or mutation". The inclusion criteria were listed as follows: (1) English or Chinese publications; (2) investigating the $16071 \mathrm{G}>2 \mathrm{G}$ polymorphism in MMP1 gene and LC risk; (3) case-control studies; (4) available data for calculating an odds ratio (OR) with corresponding 95\% confidence interval (95\% $\mathrm{CI})$ and a $\mathrm{P}$ value. The studies with overlapping cases or controls were excluded in the meta-analysis.

\section{Data extraction}

Data information was independently extracted by two reviewers (Ma and $\mathrm{Xie}$ ) for compliance with the above inclusion criteria. Any discrepancies were carefully checked by a third author and resolved by discussion. The summary data information included: first author, the year of publication, country of the study, ethnicity, total genotypes of cases and controls, study design defined as population-based case-control study (PCC) and hospital-based case-control study (HCC), and genotyping method.

\section{Statistical analysis}

Effect size was expressed as ORs with their 95\% CI to assess the strength of the potential association between
MMP1-1607 1G>2G polymorphism and LC risk. We estimated the risk under an allele model ( $2 \mathrm{G}$ vs. $1 \mathrm{G})$, a homozygous model $(2 \mathrm{G} / 2 \mathrm{G}$ vs. $1 \mathrm{G} / 1 \mathrm{G})$, a recessive model $(2 \mathrm{G} / 2 \mathrm{G}$ vs. $1 \mathrm{G} / 1 \mathrm{G}+1 \mathrm{G} / 2 \mathrm{G})$ and a dominant model $(2 \mathrm{G} / 2 \mathrm{G}+1 \mathrm{G} / 2 \mathrm{G}$ vs. $1 \mathrm{G} / 1 \mathrm{G})$, respectively. According to the heterogeneity, a fixed-effects model or a random-effects model was used to calculate pooled ORs. The study heterogeneity assumption was tested using a $\chi^{2}$-based $\mathrm{Q}$ test and a $\mathrm{P}$ value of less than 0.05 was considered representative of statistically significant. The fixed-effects model was conducted to calculate the pooled ORs if no significant heterogeneity was observed ( $Q$ test results with $\mathrm{P}>0.10$ ); otherwise, the random-effects model was conducted. We performed subgroup analyses on smoking status to evaluate smoking status-specific including smoker group and non-smoker group. Moreover, subgroup analyses were also performed based on ethnicity. Different ethnicities were categorized into Caucasians and Asians.

Sensitivity analyses were performed on individual studies to assess the stability of the results. Begg's funnel plots and Egger's tests $(\mathrm{P}<0.05$ considered statistical significance) were used to investigate the possible publication bias (Begg and Mazumdar, 1994; Egger et al., 1997). HWE was measured based on an Internet program $(\mathrm{P}>0.05)$. All statistical analyses were done with RevMan software (version5.3; Cochrane Collaboration).

\section{Results}

\section{Included study characteristics}

As illustrated in Figure 1, the initial literature search yielded 383 studies for detailed review. Forty potential relevant studies were included to assess in detail after reading the abstracts. Twenty-four additional articles were excluded for being irrelevant to LC risk and MMP1-1607 $1 \mathrm{G}>2 \mathrm{G}$ polymorphism. In addition, two studies were also excluded for the repeat data (Su et al., 2005; Fang et al., 2006). Finally, the remaining 14 studies with 6,068 cases

Table 1. Characteristics of the Studies Included in Meta-Analysis.

\begin{tabular}{lcccccc}
\hline First author & Year & Country & Ethnicity & Study design & $\begin{array}{c}\text { No. } \\
\text { (Cases/Controls) }\end{array}$ & $\begin{array}{c}\text { Genotyping } \\
\text { method }\end{array}$ \\
\hline Biondi et al., (2000) & 2000 & Italy & Caucasian & NA & $29 / 164$ & NA \\
Cheng et al., (2007) & 2007 & China & Asian & HCC & $125 / 130$ & PCR-RFLP \\
Fakhoury et al., (2012) & 2012 & Lebanon & Asian & PCC & $41 / 51$ & PCR-RFLP \\
Fang et al., (2005) & 2005 & China & Asian & PCC & $243 / 350$ & PCR-RFLP \\
González-Arriaga et al., (2008) & 2008 & Spain & Caucasian & HCC & $501 / 510$ & PCR-RFLP \\
Hart et al., (2011) & 2011 & Norway & Caucasian & PCC & $436 / 434$ & TaqMan real-time PCR \\
Klinchid et al., (2009) & 2009 & Thailand & Asian & HCC & $84 / 82$ & PCR-RFLP \\
Liu et al., (2011) & 2011 & China & Asian & PCC & $825 / 825$ & PCR-RFLP \\
Schabath et al., (2005) & 2005 & USA & Caucasian & HCC & $735 / 549$ & NA \\
Shen et al., (2018) & 2018 & China & Asian & HCC & $358 / 716$ & PCR-RFLP \\
Su et al., (2006) & 2006 & USA & Caucasian & PCC & $2014 / 1323$ & TaqMan \\
Wei et al., (2007) & 2007 & China & Asian & HCC & $71 / 75$ & PCR-RFLP \\
Zhang et al., (2006) & 2006 & China & Asian & PCC & $150 / 200$ & PCR-RFLP \\
Zhu et al., (2001) & 2001 & USA & Caucasian & PCC & $456 / 451$ & PCR-RFLP \\
\hline
\end{tabular}

PCR, polymerase chain reaction; PCR-RFLP, polymerase chain reaction-restriction fragment length polymorphism; Population-based case-control study (PCC); Hospital-based case-control study (HCC). 
Table 2. Distribution of MMP1-1607 1G>2G Genotype and Allele among Lung Cancers and Controls

\begin{tabular}{|c|c|c|c|c|c|c|c|c|c|c|c|c|}
\hline \multirow[t]{2}{*}{ First Author } & \multicolumn{3}{|c|}{ Cases (n) } & \multicolumn{3}{|c|}{ Controls (n) } & \multicolumn{2}{|c|}{ Cases (n) } & \multicolumn{2}{|c|}{ Controls (n) } & \multicolumn{2}{|c|}{ HWEa for control } \\
\hline & $1 \mathrm{G} / 1 \mathrm{G}$ & $1 \mathrm{G} / 2 \mathrm{G}$ & $2 \mathrm{G} / 2 \mathrm{G}$ & $1 \mathrm{G} / 1 \mathrm{G}$ & $1 \mathrm{G} / 2 \mathrm{G}$ & $2 \mathrm{G} / 2 \mathrm{G}$ & $1 \mathrm{G}$ & $2 \mathrm{G}$ & $1 \mathrm{G}$ & $2 \mathrm{G}$ & $\mathrm{P}$ & $\chi^{2}$ \\
\hline Biondi et al., (2000) & 7 & 16 & 6 & 42 & 86 & 36 & 30 & 28 & 170 & 158 & 0.52 & 0.413 \\
\hline Cheng et al., (2007) & 11 & 50 & 66 & 21 & 54 & 55 & 72 & 182 & 96 & 164 & 0.217 & 1.523 \\
\hline Fakhoury et al., (2012) & 5 & 17 & 19 & 7 & 16 & 28 & 27 & 55 & 30 & 72 & 0.081 & 3.047 \\
\hline Fang et al., (2005) & 24 & 84 & 135 & 51 & 105 & 194 & 132 & 354 & 207 & 493 & 0 & 27.395 \\
\hline González-Arriaga et al., (2008) & 128 & 248 & 125 & 119 & 259 & 132 & 504 & 498 & 497 & 523 & 0.712 & 0.136 \\
\hline Hart et al., (2011) & 115 & 207 & 114 & 132 & 198 & 104 & 437 & 435 & 462 & 406 & 0.081 & 3.044 \\
\hline Klinchid et al., (2009) & 9 & NA & $75^{\mathrm{a}}$ & 14 & NA & $68^{\mathrm{a}}$ & NA & NA & NA & NA & NA & NA \\
\hline Liu et al., (2011) & 74 & 323 & 428 & 100 & 367 & 358 & 471 & 1179 & 567 & 1083 & 0.691 & 0.158 \\
\hline Schabath et al., (2005) & NA & $420^{\mathrm{b}}$ & 315 & NA & $380^{\mathrm{b}}$ & 169 & NA & NA & NA & NA & NA & NA \\
\hline Shen et al., (2018) & 87 & 148 & 123 & 158 & 315 & 243 & 322 & 394 & 631 & 801 & 0.004 & 8.28 \\
\hline Su et al., (2006) & 541 & 1015 & 458 & 367 & 642 & 314 & 2097 & 1931 & 1376 & 1270 & 0.31 & 1.031 \\
\hline Wei et al., (2007) & 23 & 7 & 41 & 41 & 6 & 28 & 53 & 89 & 88 & 62 & 0 & 52.297 \\
\hline Zhang et al., (2006) & 32 & 70 & 48 & 60 & 98 & 42 & 134 & 166 & 218 & 182 & 0.865 & 0.029 \\
\hline Zhu et al., (2001) & 94 & 152 & 210 & 111 & 196 & 144 & 340 & 572 & 418 & 484 & 0.007 & 7.176 \\
\hline
\end{tabular}

HWE ${ }^{a}$, Hardy-Weinberg equilibrium; a Numbers of $1 \mathrm{G} / 2 \mathrm{G}+2 \mathrm{G} / 2 \mathrm{G}$; ${ }^{\mathrm{b}}$ Numbers of $1 \mathrm{G} / 1 \mathrm{G}+1 \mathrm{G} / 2 \mathrm{G}$; NA, not available

and 5,860 controls fulfilled our inclusion criteria. Table 1 listed the main characteristics of the studies identified for MMP1-1607 $1 \mathrm{G}>2 \mathrm{G}$ polymorphism in the meta-analysis. Among 14 studies in the present meta-analysis, there were 11 English articles (Biondi et al., 2000; Zhu et al., 2001; Fang et al., 2005; Schabath et al., 2005; Su et al., 2005; Gonzalez-Arriaga et al., 2008; Klinchid et al., 2009; Hart et al., 2011; Liu et al., 2011; Fakhoury et al., 2012; Shen et al., 2018) and 3 Chinese articles (Zhang et al., 2006; Cheng, 2007; Wei et al., 2007). Moreover, 3 articles were performed in smoking status study (Zhu et al., 2001; Fang et al., 2005; Wei et al., 2007). Of those, 7 articles were conducted on Caucasian population (Biondi et al., 2000; Zhu et al., 2001; Schabath et al., 2005; Su et al., 2006; Gonzalez-Arriaga et al., 2008; Hart et al., 2011; Fakhoury et al., 2012) and 7 on Asian population (Fang et al., 2005; Zhang et al., 2006; Cheng, 2007; Wei et al., 2007; Klinchid et al., 2009; Liu et al., 2011; Shen et al., 2018). Genotypes and allele distributions of the studies were presented in Table 2.

Quantitative meta-analysis results

The stratified summary results were shown in Table 3. In the allele model ( $2 \mathrm{G}$ vs. $1 \mathrm{G}$ ), the overall pooled effect suggested that the $2 \mathrm{G}$ allele carrier may have $19 \%$ increased LC risk compared with $1 \mathrm{G}$ the allele carrier (pooled OR $=1.19,95 \% \mathrm{CI}=1.05-1.34$, $\mathrm{P}<0.0001$ ) (Figure 2A). In the homozygous model and the recessive model, the $2 \mathrm{G} / 2 \mathrm{G}$ homozygote had a significant association with increased LC risk, compared with the $1 \mathrm{G} / 1 \mathrm{G}$ homozygote (pooled $\mathrm{OR}=1.34,95 \% \mathrm{CI}$ $=1.09-1.64, \mathrm{P}=0.003$ ) (Figure $2 \mathrm{~B}$ ) and $1 \mathrm{G} / 1 \mathrm{G}+1 \mathrm{G} / 2 \mathrm{G}$ genotype (pooled $\mathrm{OR}=1.26,95 \% \mathrm{CI}=1.06-1.49, \mathrm{P}$ $<0.0001$ ) (Figure 2C). Similarly, it was also indicated that the $2 \mathrm{G} / 2 \mathrm{G}+1 \mathrm{G} / 2 \mathrm{G}$ genotype was associated with a significantly increased LC risk, compared with the $1 \mathrm{G} / 1 \mathrm{G}$ homozygote (pooled OR $=1.21,95 \% \mathrm{CI}=1.05-1.40$, $\mathrm{P}=0.01$ ) (Figure 2D) in the dominant model.

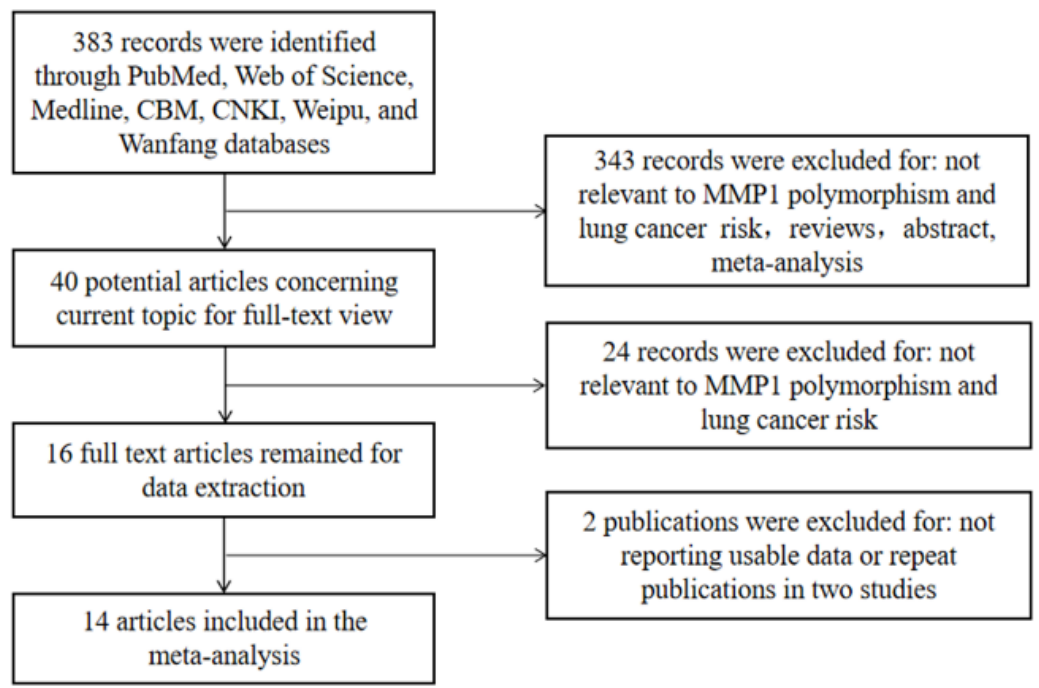

Figure 1. Flow Diagram of Included/Excluded Studies 
Table 3. The Meta-Analysis for the Associations between MMP1-1607 1G>2G Polymorphism and Risk of Lung Cancer

\begin{tabular}{|c|c|c|c|c|c|c|c|c|}
\hline \multirow{2}{*}{$\begin{array}{l}\text { Variables } \\
\text { (No. studies) }\end{array}$} & \multicolumn{2}{|l|}{$2 \mathrm{G}$ vs. $1 \mathrm{G}$} & \multicolumn{2}{|l|}{$2 \mathrm{G} / 2 \mathrm{G}$ vs. $1 \mathrm{G} / 1 \mathrm{G}$} & \multicolumn{2}{|c|}{$2 \mathrm{G} / 2 \mathrm{G}$ vs. $1 \mathrm{G} / 1 \mathrm{G}+1 \mathrm{G} / 2 \mathrm{G}$} & \multicolumn{2}{|c|}{$2 \mathrm{G} / 2 \mathrm{G}+1 \mathrm{G} / 2 \mathrm{G}$ vs. $1 \mathrm{G} / 1 \mathrm{G}$} \\
\hline & OR $(95 \% \mathrm{CI})$ & $\mathrm{P}$ & OR $(95 \% \mathrm{CI})$ & $\mathrm{P}$ & OR $(95 \% \mathrm{CI})$ & $\mathrm{P}$ & OR $(95 \% \mathrm{CI})$ & $\mathrm{P}$ \\
\hline Total (14) & $1.19[1.05,1.34]$ & $0.01^{\mathrm{a}}$ & $1.34[1.09,1.64]$ & $0.01^{\mathrm{a}}$ & $1.26[1.06,1.49]$ & $0.01^{\mathrm{b}}$ & $1.21[1.05,1.40]$ & $0.01^{\mathrm{c}}$ \\
\hline \multicolumn{9}{|c|}{ Subgroup by smoker status } \\
\hline Smoker(3) & $1.87[0.77,4.53]$ & 0.17 & $2.07[1.14,3.77]$ & 0.02 & $1.71[1.17,2.52]$ & $<0.01$ & $2.03[1.14,3.62]$ & 0.02 \\
\hline Nonsmoker(3) & $1.15[0.81,1.61]$ & 0.44 & $1.48[0.79,2.80]$ & 0.22 & $1.03[0.69,1.54]$ & 0.87 & $1.57[0.85,2.87]$ & 0.15 \\
\hline \multicolumn{9}{|c|}{ Subgroup by study design } \\
\hline Caucasian(7) & $1.08[0.93,1.26]$ & 0.3 & $1.14[0.90,1.44]$ & 0.28 & $1.18[0.91,1.54]$ & 0.21 & $1.07[0.95,1.20]$ & 0.25 \\
\hline $\operatorname{Asian}(7)$ & $1.32[1.08,1.61]$ & $<0.01$ & $1.61[1.16,2.25]$ & $<0.01$ & $1.32[1.07,1.64]$ & 0.01 & $1.46[1.11,1.94]$ & $<0.01$ \\
\hline
\end{tabular}

2G/2G VS. 1G/1G homozygote model; $2 \mathrm{G} / 2 \mathrm{G}$ VS. $1 \mathrm{G} / 1 \mathrm{G}+1 \mathrm{G} / 2 \mathrm{G}$, recessive model; $2 \mathrm{G} / 2 \mathrm{G}+1 \mathrm{G} / 2 \mathrm{G}$ VS. $1 \mathrm{G} / 1 \mathrm{G}$ dominant model; $P^{a}$ value for Z test for all studies excluding Klinchid et al and Schabath et al. $P^{b}$ value for $\mathrm{Z}$ test for all studies excluding Klinchid et al; $P^{c}$ value for $\mathrm{Z}$ test for all studies excluding Schabath et al.The bold values mean that the association is significant.
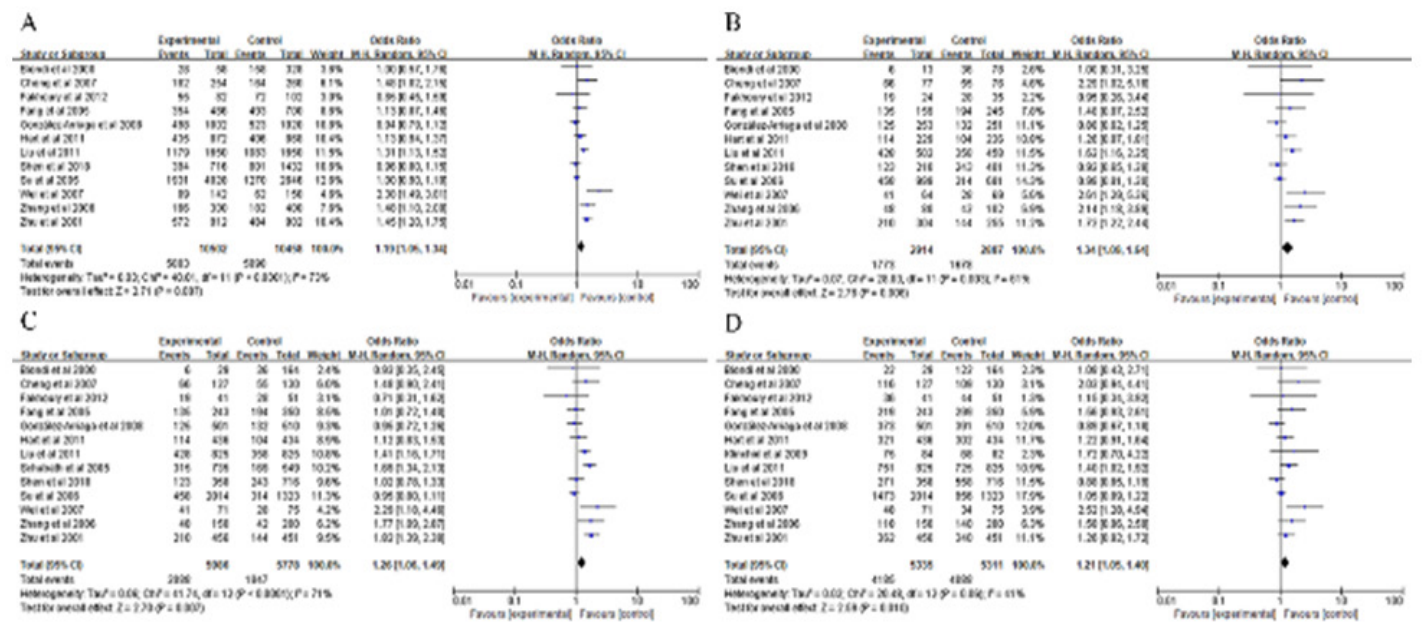

Figure 2. Meta-Analysis for the Association between Lung Cancer Risk and the MMP1-1607 1G>2G Polymorphism (A the allele model $2 \mathrm{G}$ vs. $1 \mathrm{G}$. B the homozygous model $2 \mathrm{G} / 2 \mathrm{G}$ vs. $1 \mathrm{G} / 1 \mathrm{G}$. C the recessive model: $2 \mathrm{G} / 2 \mathrm{G}$ vs. $1 \mathrm{G} / 1 \mathrm{G}$ $+1 \mathrm{G} / 2 \mathrm{G}$. D the dominant model: $2 \mathrm{G} / 2 \mathrm{G}+1 \mathrm{G} / 2 \mathrm{G}$ vs. $1 \mathrm{G} / 1 \mathrm{G})$. CI, confidence interval; OR, odds ratio.

We conducted a subgroup analysis in smoking status and another subgroup in ethnic group under various genetic models (Figure 3). Significantly elevated risks were observed among smokers under there models (the homozygous model, pooled OR $=2.07,95 \%$ $\mathrm{CI}=1.14-3.77, \mathrm{P}=0.02$; the recessive model, pooled $\mathrm{OR}=1.71,95 \% \mathrm{CI}=1.17-2.52, \mathrm{P}=0.006$; the dominant model pooled $\mathrm{OR}=2.03,95 \% \mathrm{CI}=1.14-3.62, \mathrm{P}=0.02)$, but not under an allele model (pooled $\mathrm{OR}=1.87,95 \%$
$\mathrm{CI}=0.77-4.53, \mathrm{P}=0.17)$. Thus, MMP1-1607 1G>2G polymorphism in smokers may have a higher increase LC risk under the homozygous model, the recessive model and the dominant model. In ethnicity subgroup analyses (Figure 4), significantly increased risks were observed in Asian group under four models: $2 \mathrm{G}$ vs. $1 \mathrm{G}$, pooled $\mathrm{OR}=1.32,95 \% \mathrm{CI}=1.08-1.61, \mathrm{P}=0.006$ (Figure 4A); $2 \mathrm{G} / 2 \mathrm{G}$ vs. $1 \mathrm{G} / 1 \mathrm{G}$, pooled $\mathrm{OR}=1.61,95 \% \mathrm{CI}=1.16-2.25$, $\mathrm{P}=0.005$ (Figure $4 \mathrm{~B}$ ); $2 \mathrm{G} / 2 \mathrm{G}$ vs. $2 \mathrm{G} 1 \mathrm{G}+1 \mathrm{G} / 1 \mathrm{G}$, pooled

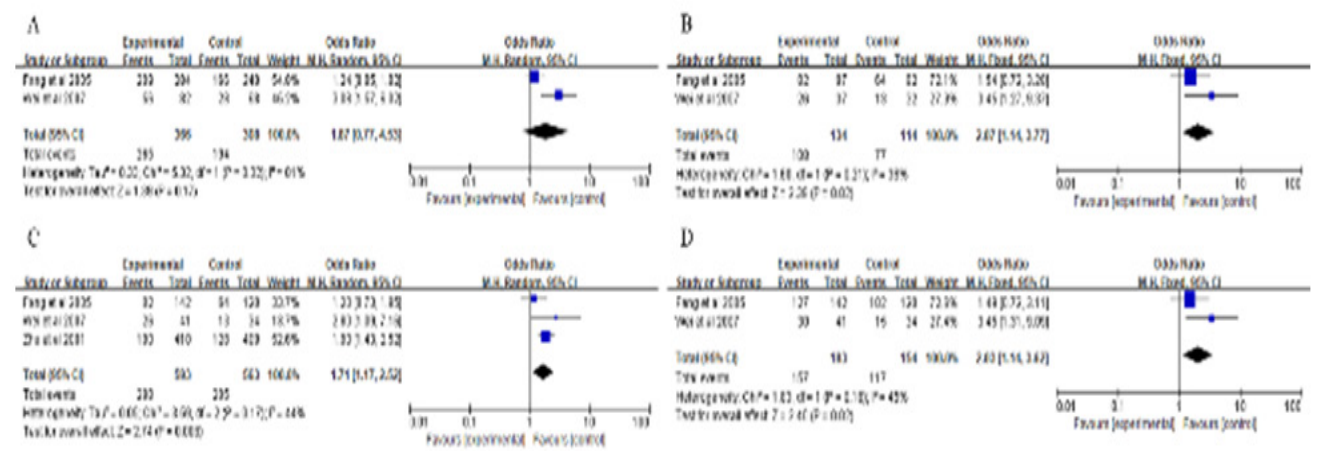

Figure 3. Meta-Analysis with a Fixed-Effects Model for the Association between Lung Cancer Risk and the MMP1-1607 1G>2G Polymorphism in Smoking Studies with Different Genotypes (A the allele model 2G vs. 1G. B the homozygous model $2 \mathrm{G} / 2 \mathrm{G}$ vs. $1 \mathrm{G} / 1 \mathrm{G}$. $\mathrm{C}$ the recessive model: $2 \mathrm{G} / 2 \mathrm{G}$ vs. $1 \mathrm{G} / 1 \mathrm{G}+1 \mathrm{G} / 2 \mathrm{G}$. D the dominant model: $2 \mathrm{G} / 2 \mathrm{G}+1 \mathrm{G} / 2 \mathrm{G}$ vs. $1 \mathrm{G} / 1 \mathrm{G})$. CI, confidence interval; OR, odds ratio. 


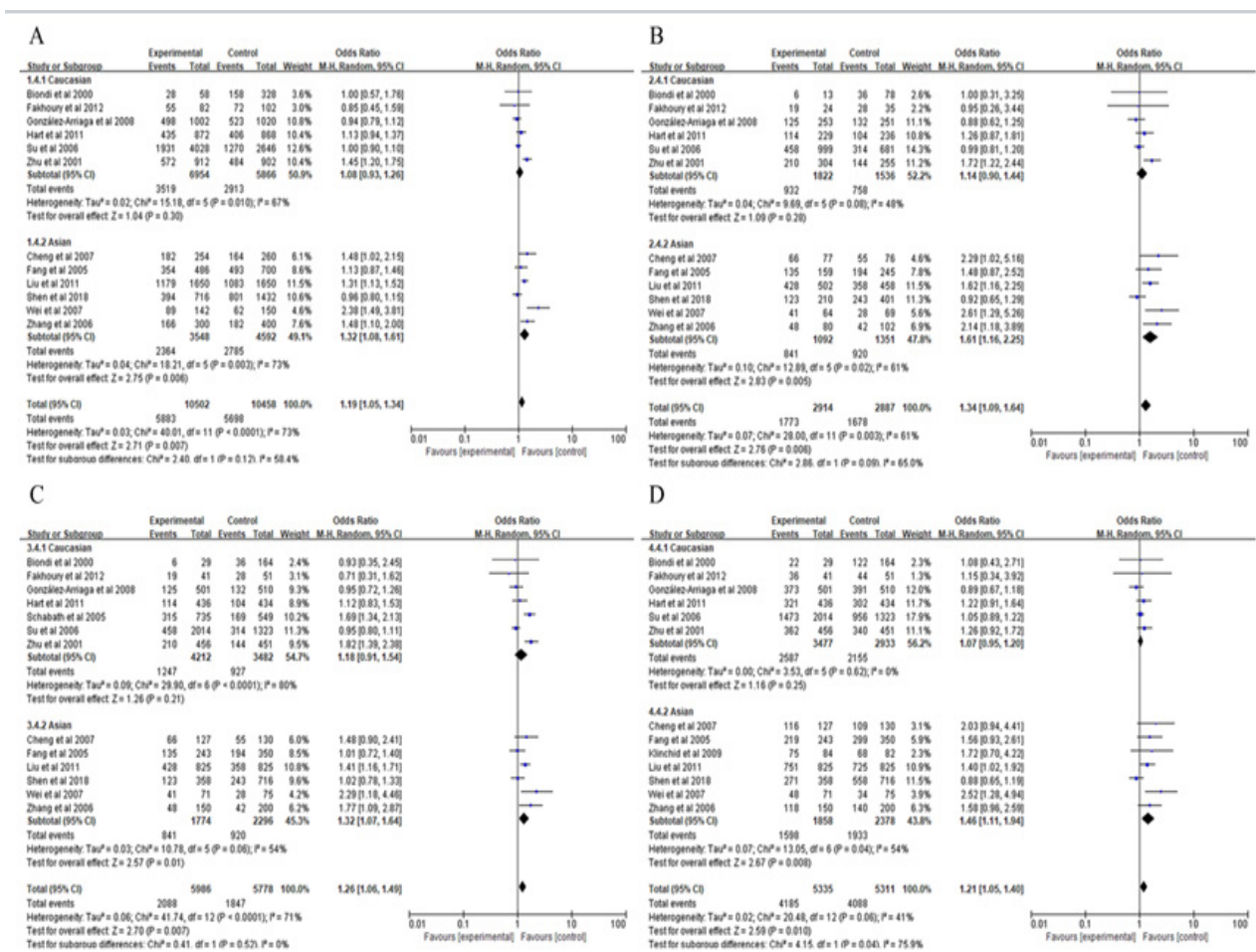

Figure 4. Meta-Analysis with a Fixed-Effects Model for the Association between Lung Cancer Risk and the MMP1-1607 $1 \mathrm{G}>2 \mathrm{G}$ Polymorphism in Subgroup Analysis by Ethnicity (A the allele model 2G vs. 1G. B the homozygous model $2 \mathrm{G} / 2 \mathrm{G}$ vs. $1 \mathrm{G} / 1 \mathrm{G}$. $\mathrm{C}$ the recessive model: $2 \mathrm{G} / 2 \mathrm{G}$ vs. $1 \mathrm{G} / 1 \mathrm{G}+1 \mathrm{G} / 2 \mathrm{G}$. D the dominant model: $2 \mathrm{G} / 2 \mathrm{G}+1 \mathrm{G} / 2 \mathrm{G}$ vs. $1 \mathrm{G} / 1 \mathrm{G})$. CI, confidence interval; OR, odds ratio.

$\mathrm{OR}=1.32,95 \% \mathrm{CI}=1.07-1.64, \mathrm{P}=0.01$ (Figure $4 \mathrm{C}$ ); $2 \mathrm{G} / 2 \mathrm{G}+1 \mathrm{G} / 2 \mathrm{G}$ vs. $1 \mathrm{G} / 1 \mathrm{G}$, pooled $\mathrm{OR}=1.46$ (Figure $4 \mathrm{D})$, $95 \% \mathrm{CI}=1.11-1.94, \mathrm{P}=0.008$. However, no significant association was observed in non-smoker group and Caucasians under four genetic models. Thus, MMP1-1607 $1 \mathrm{G}>2 \mathrm{G}$ polymorphism increased LC risk in Asians.

\section{Sensitivity analysis}

In the present meta-analysis, we carried out a sensitivity analysis through sequential omission of a single study to evaluate the stability of the results. The results indicated that no individual study dominantly affected the overall ORs. Statistically similar outcomes were obtained in total studies (all $\mathrm{P}>0.05$ ), conforming the stable results (data not shown).

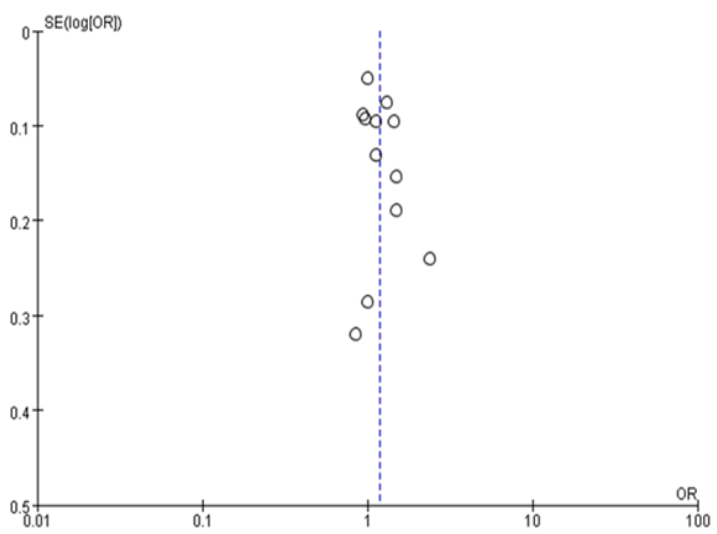

Figure 5. Begg's Funnel Plot for Publication Bias in Selection of Studies on the MMP1-1607 1G>2G Polymorphism (2G vs. $1 \mathrm{G})$. OR, odds ratio.

\section{Publication bias}

We used the funnel plots and Egger's tests to assess the publication bias. The graphical funnel plot of MMP1-1607 $1 \mathrm{G}>2 \mathrm{G}$ polymorphism under $2 \mathrm{G}$ vs. $1 \mathrm{G}$, the allele model, did not show any evidence of obvious asymmetry (Figure 5). The Egger's tests showed that there were no publication bias (all $\mathrm{P}>0.05$ ) (data not shown).

\section{Discussion}

Our meta-analysis including 14 studies with 6068 cases and 5860 controls suggested that MMP1-1607 $1 \mathrm{G}>2 \mathrm{G}$ polymorphism was associated $\mathrm{LC}$ risk under four genetic models: $2 \mathrm{G}$ vs. $1 \mathrm{G}$ model (pooled $\mathrm{OR}=1.19$, $95 \% \mathrm{CI}=1.05-1.34) ; 2 \mathrm{G} / 2 \mathrm{G}$ vs. $1 \mathrm{G} / 1 \mathrm{G}$ (pooled $\mathrm{OR}=$ $1.34,95 \% \mathrm{CI}=1.09-1.64) ; 2 \mathrm{G} / 2 \mathrm{G}$ vs. $1 \mathrm{G} / 1 \mathrm{G}+1 \mathrm{G} / 2 \mathrm{G}$ (pooled OR $=1.26,95 \% \mathrm{CI}=1.06-1.49$ ); $2 \mathrm{G} / 2 \mathrm{G}+1 \mathrm{G} / 2 \mathrm{G}$ vs. $1 \mathrm{G} / 1 \mathrm{G}$ (pooled $\mathrm{OR}=1.21,95 \% \mathrm{CI}=1.05-1.40$ ). It suggested that MMP1-1607 $1 \mathrm{G}>2 \mathrm{G}$ polymorphism was significantly associated with increased LC risk.

MMP1, a member of MMP in degrading the interstitial collagen types I, II, III, is constitutively expressed in normal physiologic conditions at a low level, while in pathologic conditions its expression may increase remarkably especially in cancer. MMP1-1607 1G>2G polymorphism may have impacts on the susceptibility to cancer risk by modulating MMP1 expression levels. A recent meta-analysis study explored the association between MMP1 polymorphism and cancer susceptibility (Han et al., 2014). It has been proved that MMP1-1607 $1 \mathrm{G}>2 \mathrm{G}$ polymorphism elevated risk was found regarding lung cancer, colorectal cancer, head and neck cancer and 
bladder cancer. Xiao et al., (2012) also have reported that $16071 \mathrm{G}>2 \mathrm{G}$ polymorphism in the MMP1 increased LC risk in Asians. Our results supported the conception that MMP1-1607 $1 \mathrm{G}>2 \mathrm{G}$ polymorphism was a genetic susceptibility risk factor of LC.

It is well recognized that smoking cigarettes can cause LC. Many carcinogens are present in cigarette smoke, some of which can stimulate the growth of lung cancer cells (Wen et al., 2016). Interactions with some gene polymorphisms and smoking are associated with increased risk of LC (Herbst et al., 2008). In the subgroup, we analyzed the smoking status concluding 3 studies to evaluate relationship between smoking and MMP1-1607 $1 \mathrm{G}>2 \mathrm{G}$ for LC. Strongly significant associations were observed in smokers under three genetic models: $2 \mathrm{G} / 2 \mathrm{G}$ vs. $1 \mathrm{G} / 1 \mathrm{G}$ (pooled $\mathrm{OR}=2.07,95 \% \mathrm{CI}=1.14-3.77$ ); $2 \mathrm{G} / 2 \mathrm{G}$ vs. $1 \mathrm{G} / 1 \mathrm{G}+1 \mathrm{G} / 2 \mathrm{G}$ (pooled $\mathrm{OR}=1.71,95 \% \mathrm{CI}$ $=1.17-2.52) ; 2 \mathrm{G} / 2 \mathrm{G}+1 \mathrm{G} / 2 \mathrm{G}$ vs. $1 \mathrm{G} / 1 \mathrm{G}$ (pooled $\mathrm{OR}=$ $2.03,95 \% \mathrm{CI}=1.14-3.62)$. These results indicated that there were significant associations with higher LC risks under the homozygous model, the recessive model, and the dominant model. To the best of our knowledge, this is the first meta-analysis to explore the association between MMP1-1607 $1 \mathrm{G}>2 \mathrm{G}$ polymorphism and $\mathrm{LC}$ for smoking population, involving 593 cancer cases and 563 controls. Zhu et al. investigated that the $2 \mathrm{G}$ allele of the MMP1 promoter single-nucleotide polymorphism had been associated with increased LC susceptibility in Caucasians, especially among smokers (Zhu et al., 2001). However, in our subgroup analyses by ethnicity, the association was still obvious in Asians, but there was no association in Caucasians. Our results were consistent with previous meta-analyses (Xiao et al., 2012; Lu et al., 2015). The total sample sizes of Caucasians might be limited and the discrepancies between Asians and Caucasians might be due to some factors, such as complicated environment and various genetic backgrounds. In different populations, the inconsistent result still demonstrated the importance on assessing genetic effects on disease development and progression.

There were some advantages in our meta-analysis compared with previous studies. First of all, updated statistics for the MMP1-1607 $1 \mathrm{G}>2 \mathrm{G}$ polymorphism and LC risk were based on a larger size of cases and control subjects. Then, the symmetrical funnel plots and Egger's tests showed that there were no publication bias, suggesting the unbiased pooled results. Finally, we investigated the smoking status to analyze the connection between smoking and $16071 \mathrm{G}>2 \mathrm{G}$ polymorphism of MMP1 for LC risk. However, this meta-analysis had several limitations that should be addressed. Firstly, the eligible studies were written in English or Chinese, which may cause potential bias for missing publications. Secondly, the insufficient genotype data in the studies of Klinchid et al. and Schabath et al. may affect our results. Thirdly, the quantity of objectives were limited especially in smoking subgroup. Consequently, the total samples require to be expanded. Fourthly, despite subgroups being conducted by smoking and ethnicity, there were still a few potential factors that may be ignored, such as age, gender and family history. Thus, further studies should be conducted considering the gene-environment interactions.

In conclusion, the present meta-analysis showed MMP1-1607 1G $>2 \mathrm{G}$ polymorphism was a risk factor for developing LC risk. Subgroup analyses based on smoking suggested a higher association between MMP1-1607 $1 \mathrm{G}>2 \mathrm{G}$ polymorphism and $\mathrm{LC}$ risk under the homozygous model $2 \mathrm{G} / 2 \mathrm{G}$ vs. $1 \mathrm{G} / 1 \mathrm{G}$, the recessive model $2 \mathrm{G} / 2 \mathrm{G}$ vs. $1 \mathrm{G} / 1 \mathrm{G}+1 \mathrm{G} / 2 \mathrm{G}$, the dominant model $2 \mathrm{G} / 2 \mathrm{G}+1 \mathrm{G} / 2 \mathrm{G}$ vs. $1 \mathrm{G} / 1 \mathrm{G}$. And there was a significant association between the MMP1-1607 $1 \mathrm{G}>2 \mathrm{G}$ polymorphism and LC risk in Asians. Moreover, future studies are still required with a larger population and detailed environmental backgrounds.

\section{Acknowledgments}

The authors would like to thank all the participants enrolled in the work. This work was supported by Post-Doctor Research Project (2018HXBH032), and Science and Technology Program for Public Wellbeing of Chengdu (2015-HM01-00224-SF).

\section{References}

Begg CB, Mazumdar M (1994). Operating characteristics of a rank correlation test for publication bias. Biometrics, 50, 1088-101.

Biondi ML, Turri O, Leviti S, et al (2000). MMP1 and MMP3 polymorphisms in promoter regions and cancer. Clin Chem, 46, 2023-4.

Bray F, Ferlay J, Soerjomataram I, et al (2018). Global cancer statistics 2018: GLOBOCAN estimates of incidence and mortality worldwide for 36 cancers in 185 countries. $C A$ Cancer J Clin, 68, 394-424.

Cheng XL (2007). Correlation of single nucleotide polymorphism in the matrix metalloproteinase-1 promoter(-1607) $1 \mathrm{G} / 2 \mathrm{G}$ with risk of lung cancer. Shanxi Med Univ, 38, 777-9

Egger M, Davey Smith G, Schneider M, et al (1997). Bias in meta-analysis detected by a simple, graphical test. $B M J$, 315, 629-34.

Fakhoury H, Noureddine S, Chmaisse HN, et al (2012). MMP1-1607 ( $1 \mathrm{G}>2 \mathrm{G})$ polymorphism and the risk of lung cancer in Lebanon. Ann Thorac Med, 7, 130-2.

Fang SM, Jin X, Li Y, et al (2006). Correlation of genetic polymorphisms of matrix metalloproteinase-1 with non-small cell lung carcinoma. [Article in Chinese]. Tumour, 26, 64-7.

Fang SM, Jin X, Wang R, et al (2005). Polymorphisms in the MMP1 and MMP3 promoter and non-small cell lung carcinoma in North China. Carcinogenesis, 26, 481-6.

Gonzalez-Arriaga P, Lopez-Cima MF, Fernandez-Somoano A, et al (2008). Polymorphism $+17 \mathrm{C} / \mathrm{G}$ in matrix metalloprotease MMP8 decreases lung cancer risk. BMC Cancer, 8, 378.

Han G, Wei Z, Lu Z, et al (2014). Association between matrix metalloproteinase $1-16071 \mathrm{G}>2 \mathrm{G}$ polymorphism and cancer risk: a meta-analysis including 19706 subjects. Int J Clin Exp Med, 7, 2992-9.

Hart K, Landvik NE, Lind H, et al (2011). A combination of functional polymorphisms in the CASP8, MMP1, IL10 and SEPS1 genes affects risk of non-small cell lung cancer. Lung Cancer, 71, 123-9.

Herbst RS, Heymach JV, Lippman SM (2008). Lung cancer. N Engl J Med, 359, 1367-80.

Hu J, Pan J, Luo ZG (2012). MMP1 rs 1799750 single nucleotide 
polymorphism and lung cancer risk: A meta-analysis. Asian Pac J Cancer Prev, 13, 5981-4.

Klinchid J, Chewaskulyoung B, Saeteng S, et al (2009). Effect of combined genetic polymorphisms on lung cancer risk in northern Thai women. Cancer Genet Cytogenet, 195, 143-9.

Liu L, Wu J, Wu C, et al (2011). A functional polymorphism $(-1607$ 1G-->2G) in the matrix metalloproteinase-1 promoter is associated with development and progression of lung cancer. Cancer, 117, 5172-81.

Lu LL, Sun YJ, Li YQ, et al (2015). The polymorphism MMP1 $-1607(1 \mathrm{G}>2 \mathrm{G})$ is associated with a significantly increased risk of cancers from a meta-analysis. Tumour Biol, 36, 1685-93.

Malhotra J, Malvezzi M, Negri E, et al (2016). Risk factors for lung cancer worldwide. Eur Respir J, 48, 889-902.

McIntyre A, Ganti AK (2017). Lung cancer-A global perspective. $J$ Surg Oncol, 115, 550-4.

Nelson AR, Fingleton B, Rothenberg ML, et al (2000). Matrix metalloproteinases: biologic activity and clinical implications. J Clin Oncol, 18, 1135-49.

Rutter JL, Mitchell TI, Buttice G, et al (1998). A single nucleotide polymorphism in the matrix metalloproteinase-1 promoter creates an Ets binding site and augments transcription. Cancer Res, 58, 5321-5.

Schabath MB, Delclos GL, Martynowicz MM, et al (2005). Opposing effects of emphysema, hay fever, and select genetic variants on lung cancer risk. Am J Epidemiol, 161, 412-22.

Shen TC, Chang WS, Tsai CW, et al (2018). The contribution of matrix metalloproteinase-1 promoter genotypes in Taiwan lung cancer risk. Anticancer Res, 38, 253-7.

Su L, Zhou W, Asomaning K, et al (2006). Genotypes and haplotypes of matrix metalloproteinase 1, 3 and 12 genes and the risk of lung cancer. Carcinogenesis, 27, 1024-9.

Su L, Zhou W, Park S, et al (2005). Matrix metalloproteinase-1 promoter polymorphism and lung cancer risk. Cancer Epidemiol Biomarkers Prev, 14, 567-70.

Vincenti MP, White LA, Schroen DJ, et al (1996). Regulating expression of the gene for matrix metalloproteinase-1 (collagenase): mechanisms that control enzyme activity, transcription, and mRNA stability. Crit Rev Eukaryot Gene Expr, 6, 391-411.

Wei WQ, Liang XQ, Wen XP (2007). The Association of MMP$1-1607(1 \mathrm{G} \rightarrow 2 \mathrm{G})$ single nucleotide polymorphism with the susceptibility to non-small cell lung carcinoma in Guizhou Han nationality. Guiyang Med Coll, 12, 267-9.

Wen L, Jiang K, Yuan W, et al (2016). Contribution of variants in CHRNA5/A3/B4 gene cluster on chromosome 15 to Tobacco smoking: From genetic association to mechanism. Mol Neurobiol, 53, 472-84.

Xiao XY, Wang XD, Zang DY (2012). MMP1-1607 1G/2G polymorphism and lung cancer risk: a meta-analysis. Tumour Biol, 33, 2385-92.

Zhang WQ, Lin H, Zhou YA, et al (2006). Association of MMP1 -1607(1G>2G)single nucleotide polymorphism with susceptibility to lung cancer in Northwestern Chinese population of Han nationality. Zhonghua Yi Xue Yi Chuan Xue Za Zhi, 23, 313-5.

Zhu Y, Spitz MR, Lei L, et al (2001). A single nucleotide polymorphism in the matrix metalloproteinase-1 promoter enhances lung cancer susceptibility. Cancer Res, 61, 7825-9.

\section{cc) (i) (8)}

This work is licensed under a Creative Commons AttributionNon Commercial 4.0 International License. 